\title{
Prestudy on Power Management of a Cut-To-Length Forest Harvester with a Hydraulic Hybrid System
}

\author{
K. Einola \\ Ponsse Plc, Vieremä, Finland \\ E-mail: kalle.einola@ponsse.com
}

\begin{abstract}
A Cut-To-Length (CTL) forest harvester is used for felling, delimbing and bucking of the tree stems as forwarder is used to forward the logs cut to length to roadside landing for highway transport to the refining facilities like saw- and pulp \& paper mills. Fuel consumption of forest harvesting operation is becoming a more and more important cost factor as the fuel prices are raising constantly.

A number of studies exist on various hybrid systems related to on- \& off-highway vehicles and work machines. This paper deals with technological possibilities and potential to cut down fuel consumption of a CTL harvester by implementation of a hydraulic hybrid system that is mainly designed to take care of the highest power demands. In order to be successful in this aim, a detailed analysis of the work cycle and present power management and transmission systems are needed. Engine load data together with relevant Arcnet and CAN bus messages as well as needed hydraulic system parameters are logged during actual work in order to understand the actual nature of the application in terms of work cycle.

This study is focusing on a hydraulic hybrid system, as it seems to be an applicable solution to mobile work machinery in question. However - a background review of other hybrid solutions is also given. Some of the relevant advantages of a hydraulic hybrid system in forest machine application are also explained in this paper.

Based on the prestudy and analysis on the work cycle - a promising potential for hydraulic hybrid system can be seen in a CTL harvester. Future work to be done is proposed to include simulations to make a more detailed dimensioning of the components and design of the system possible already before building an actual test setup.
\end{abstract}

Keywords: Hydraulic hybrid, forest machinery, cut-to-length harvester

\section{Introduction}

Steadily growing percentage of industrial wood raw material is harvested mechanically and increasingly carried out with modern Cut-To-Length (CTL) machines. Typical CTL forestry operation is carried out with two principal machine units, a harvester and a forwarder. A CTL harvester is used for mechanized felling, delimbing and bucking of the tree stems whereas forwarder is used to forward the logs already cut-to-length to roadside landing for highway transport to the forest industry facilities like saw- and pulp/paper mills. In the competing TL method a larger number and variety of equipment is typically needed on one site and often four individual machine types are used[14]: feller-buncher, skidder, loader and processor.

Despite of the fact that CTL machinery is often considered more fuel efficient than Tree-Length (TL) method and machinery used - the fuel consumption of CTL machinery is also becoming a more and more important cost factor. Fuel prices are supposed to continue rising globally which is coming into a conflict with the forest industry's objective of still lowering the harvesting cost per timber cubic meter in the future.

\section{Review on the recent development on hybrid systems - both in industry and research}

A brief review on the development of various hybrid solutions in both on- and off-highway vehicles and mobile work machines is given. Many of the discussed hybrid systems are still in prototype or demonstration phase but some of them already in serial production. In this study the term hybrid is widely understood as a system with more than one power source - even though only a single primary power source typically exist in vehicles and mobile work machines.

\subsection{On-highway vehicle hybrids}

During the last decade, a number of electric hybrid driven on-highway vehicles have entered serial production. In these vehicles the fuel economy has typically been 
improved by accompanying an internal combustion engine (ICE) with one or more suitable assisting electric motors that are connected to the energy storage system like Lithium-ion battery pack. Typically a suitable battery management system (BMS) is also needed. This way the ICE can be dimensioned for lower peak load in a more optimal way to suit the average drive conditions. Of course the other approach is to use the stored hybrid power as a hybrid-boost functionality, often both functionalities can be incorporated into the same system. Brake energy can also effectively be recovered into the energy storage of the system. The electric motor can take care of the highest power demands and on the other hand make it possible to use start/stop functionality which is very useful in stop-andgo urban traffic. Remarkable fuel savings and $\mathrm{CO}_{2}$ emission reduction have been proven especially in urban driving also some all-electric range can be provided with large enough energy storage.

Both series and parallel hybrid designs exist in passenger car segment and all the time more models will be available. Earlier the ICE of electric hybrid passenger cars was typically chosen to be petrol driven, but more recently some European car manufacturers have started to turn towards diesel-electric hybrids also in passenger cars [13]. Mercedes-Benz is also introducing a new functionality named "sailing" in this E300 Bluetec Hybrid model which means that diesel engine is automatically shut down and disengaged from the powertrain also on higher speeds up to $160 \mathrm{~km} / \mathrm{h}$ when the electric drive is able to maintain the constant speed. In other words on flat gradient or decline, like motorway conditions an all electric drive is used as long as there is stored energy available or the driver wants to take over.

Hydraulic hybrids in on-highway applications have so far been mainly tested and used in heavier commercial vehicles that typically drive in urban conditions and a remarkable amount of acceleration and braking of the vehicle - with relatively heavy vehicle gross weight is included in the daily work cycle. In this kind of application the payback time for a hybrid drive system can easier be short enough to make it also commercially viable. As an example garbage and delivery trucks have been the most potential application environments for this kind of technology. A well known commercial hydraulic launch assist (HLA) system is delivered by Eaton Corporation. This system is claimed to deliver 15 to $30 \%$ better fuel economy and simultaneously more than four times longer brake life [21]. These numbers have obviously convinced a number of large logistics companies and the HLA system is already in use in commercial vehicles.

Interestingly - more attention is given on hydraulic hybrids also on small passenger cars as the cost level hydraulic hybrid seems to be very competitive yet an excellent fuel efficiency can expected. PSA Peugeot Citroen launched recently a hydraulic hybrid platform called Hybrid Air and states that it will be available on B and C segment passenger cars as well as some commercial vehicles [20]. This platform including hydraulic hybrid components like high and low pressure accumulators as well as hydraulic pump and motor with the needed hydraulic lines can be seen in fig 1 .

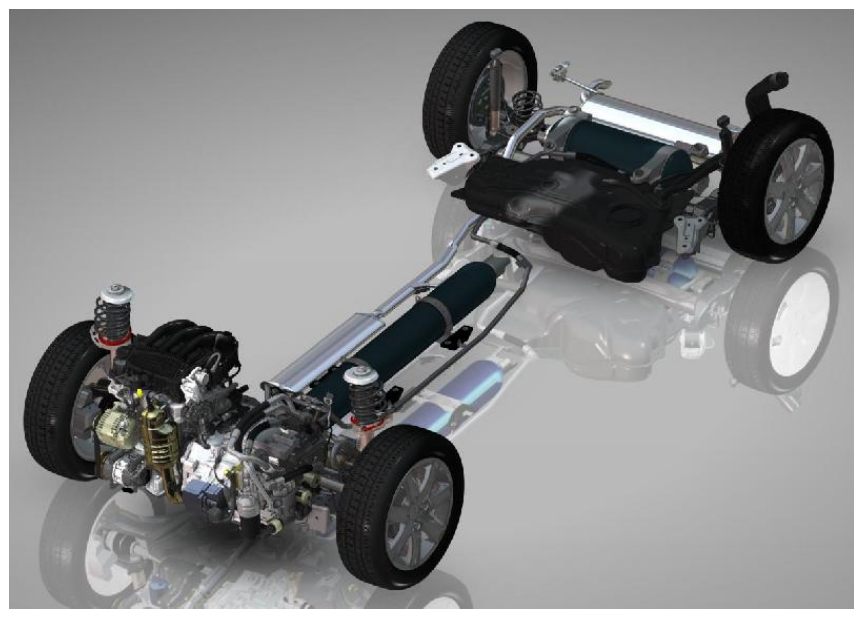

Figure 1. "Hybrid Air" petrol full-hybrid - by PSA Peugeot Citroen. A hydraulic hybrid shows great potential in passenger cars as well. [20]

The manufacturer of Hybrid Air is claiming that the technology will be affordable and provide up to $45 \%$ fuel savings in city traffic when compared to conventional engines with the same power rating. Furthermore it is emphasized that the environmental footprint is significantly reduced and the materials used throughout the power system are plentiful and easily recyclable for a lower overall impact on the environment. In contrast to hydraulic hybrid this is not the case with e.g. rare-earth elements typically used in modern high power electric energy storage systems. It is also stated that hydraulic hybrid technology is viable in all markets and climates regardless of the extent of the service network, which is a great advantage. According to the manufacturer more than 80 patent applications have been filed related to this technology [20].

In fig 2 vehicle power systems price is compared with $\mathrm{CO}_{2}$ emissions. Manufacturer is claiming that the trade-off between $\mathrm{CO} 2$ and power system price is simply unmatched by any of the current other hybrid technologies.

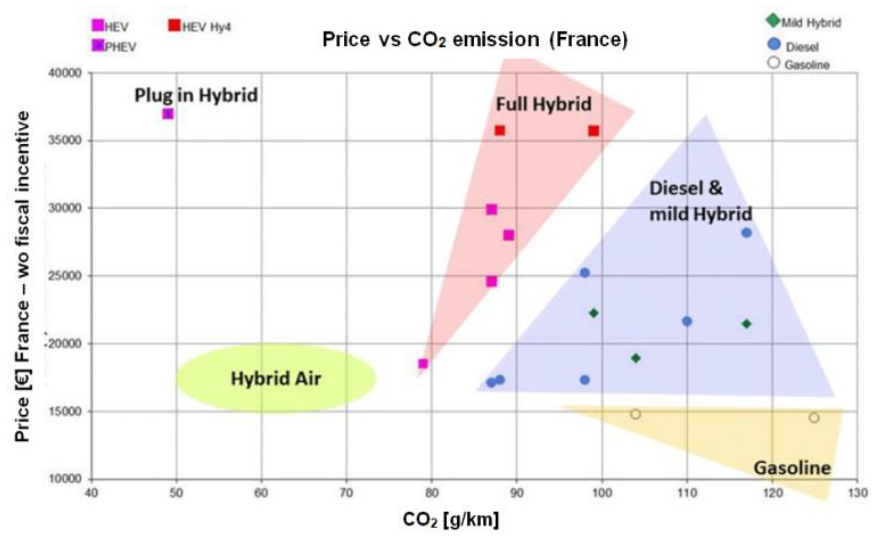

Figure 2. Price vs. $\mathrm{CO}_{2}$ emission comparison by PSA Peugeot Citroen. [20] 
Furthermore an interesting electro hydraulic hybrid has been proposed to be used in a commuter car in a study by Innas BV [18]. The vehicle driveline concept is based on a serial hydraulic hybrid replacing the mechanical drive transmission. Studied driveline is based on a hydraulic grid which makes the implementation of an electric power source easy. The concept is said to combine the optimal capabilities of both hydraulic and electric driveline and energy storage. These capabilities include reasonably long all-electric operating range of up to $25 \mathrm{~km}$ that gets very useful in urban zero emission traffic, and on the other hand performance characteristics comparable with reference car thanks to the hydraulic hybrid system which works as the backbone of the drive system. Fuel consumption as well as $\mathrm{CO}_{2}$ emission were stated to be more than $30 \%$ lower than the values with respective reference car - even with the hydraulic driving in use only.

\subsection{Off-highway vehicle and work machine hybrids}

Various hybrid systems are also entering mobile work machine business and the most popular application for the hybrid drive seems to be a hydraulic excavator with rotatable upper structure. This design can generally be taken as a machine type with a high production volume in the industry and where the fuel saving potential is thus remarkable. Typically in the hybrid excavators the swing function of the upper structure is driven with an electric motor and this way swing function braking energy can be recovered to energy storage system like ultra capacitor or battery pack or their combination. A large number of patents publications exist related to electrical hybrid systems and especially control of such systems [4]. The hybrid system usually also includes a power generation electric motor that is typically mounted on the pump divider gear connected to the main drive train. This way also parallel hybrid functionality can be added to the machine in a feasible way and extra power is available to all or most of the power train of the machine if needed.

In fig 3 below the working principle of a Komatsu hybrid excavator is explained.

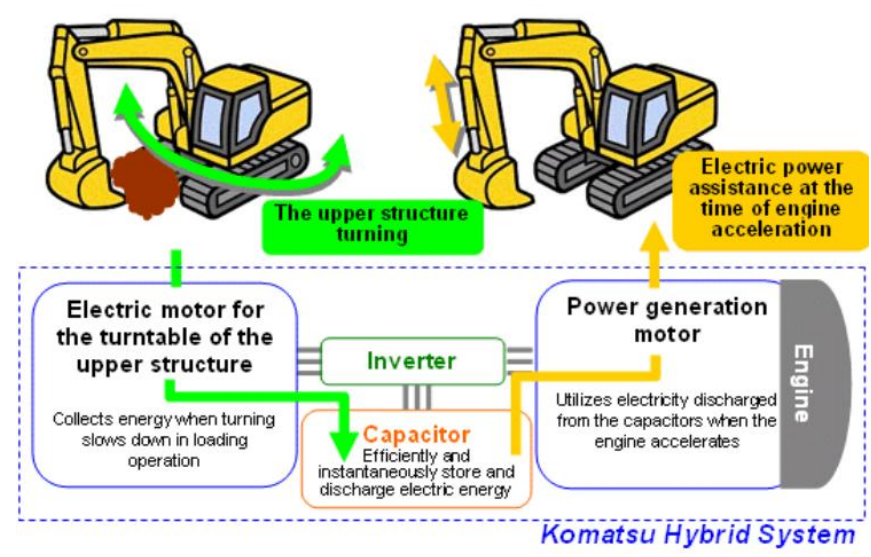

Figure 3. Working principle of the electric hybrid system of a Komatsu hybrid excavator.[9]
Mobile work machine manufacturer Komatsu Ltd. [9] claims that their PC200-8 Hybrid excavator achieves 25\% fuel savings on average use. Fuel saving potential is however strongly linked to the actual work cycle of such an excavator and as the manufacturer is stating, savings can also be remarkably higher if upper structure swing function has a more important role in the work cycle. This is quite natural as swing function is the only function with energy recovery functionality. This is emphasized in fig 4.

Fuel Consumption Measured Data from Actual Use

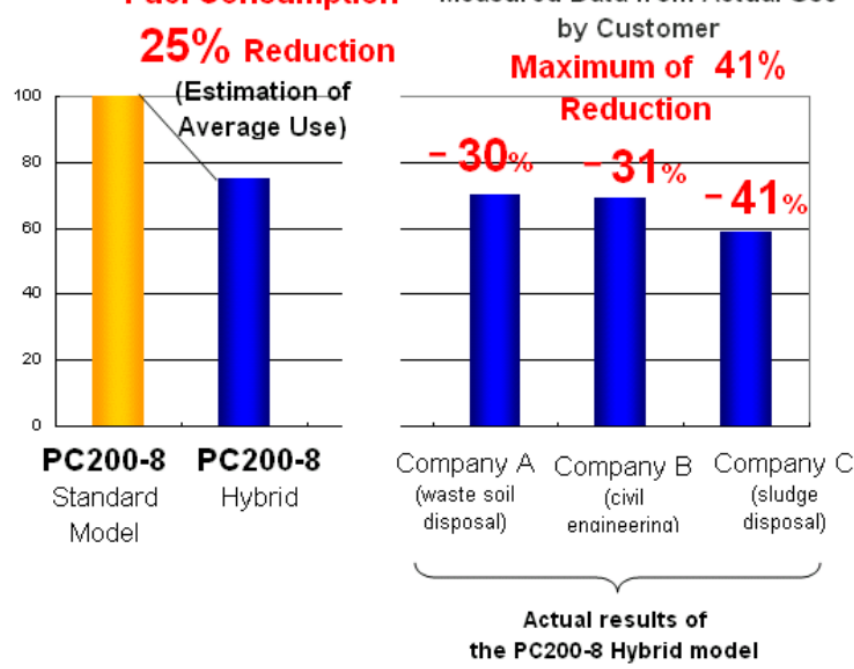

Figure 4. Claimed fuel consumption reductions of a Komatsu PC200-8 Hybrid Excavator.[9]

Electric hybrid systems are tested also in recent CTL forest machinery, for example a Swedish manufacturer El-Forest $\mathrm{Ab}$ has already for a number of years tested and developed forwarder with electric hybrid system for both drive transmission [3] in serial hybrid design as well as boom system with parallel hybrid functionality. El-Forest B12 forwarder is stated [10] to provide 25\% lower fuel consumption than respective machine with traditional power transmission. A little later this same electric hybrid technology by El-Forest Ab has also been fitted to a CTL harvester manufactured by a Finnish company ProSilva Plc. In this harvester application the electric hybrid system is only driven in parallel mode, assisting the diesel engine serving as the prime mover of the hydraulic systems of the machine. ProSilva is claiming [11] that in their 910EH harvester the diesel engine was downsized from $155 \mathrm{~kW} 6$ cylinder engine to a $60 \mathrm{~kW} 4$-cylinder unit without compromising the harvesting power. If this is taken as a matter of fact it can be concluded that a remarkable downsizing potential really exists.

A simple hydraulic hybrid solution for a CTL harvester was studied and tested by a German company HSM GmbH [5]. In this machine a hydraulic accumulator with volume of 60 liters was connected in parallel with the variable displacement pump in order to feed the same harvester head hydraulic circuit. Hydraulic accumulator was connected to the standard hydraulic system via safety valve block and $2 / 2$ charge and discharge on/off valves as seen in fig 5 [5]. 


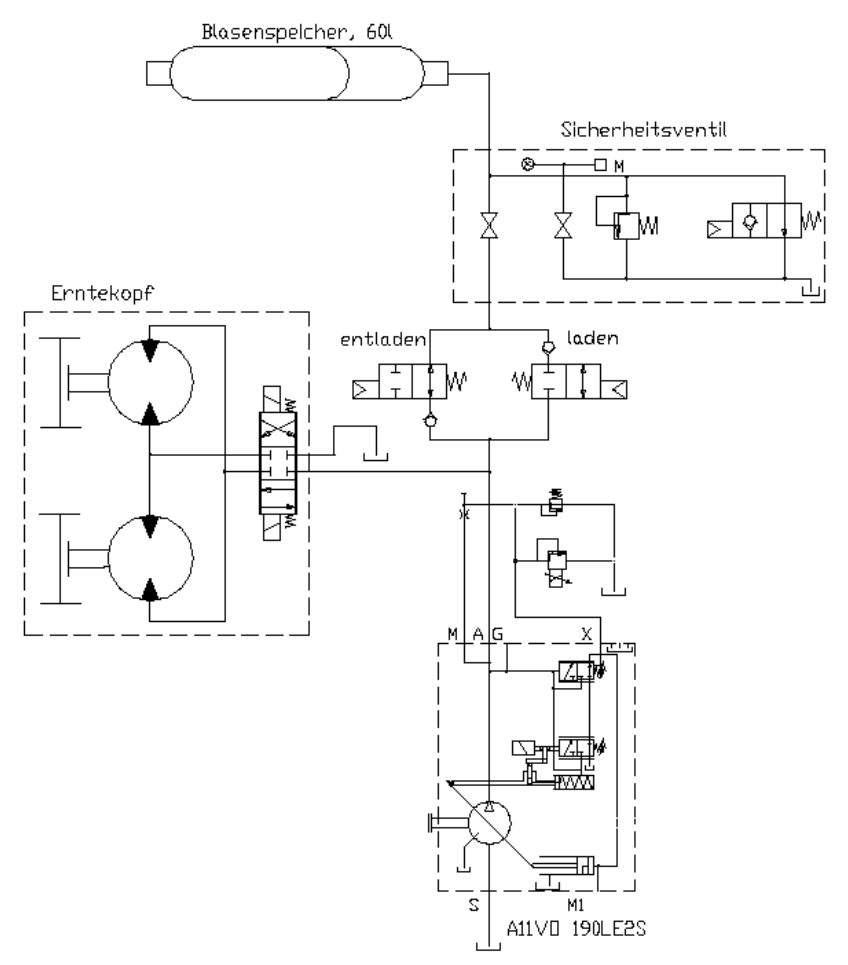

Figure 5. Hydraulic diagram of HSM $405 \mathrm{H} 2$ harvester with the studied energy storage system. [5]

The following aims were addressed for the studied system: more even engine load, higher delimbing power, better dynamics for delimbing feed start, lower pressure peaks during deceleration of delimbing and finally the shifting of the engine operation point to best efficiency area. The energy storage capacity of the used hydraulic accumulator, ca. $360 \mathrm{~kJ}$ was in the study used for a hybrid boost which was roughly calculated to be able to increase the available power from $175 \mathrm{~kW}$ diesel engine ca. $50 \%$ say $90 \mathrm{~kW}$ for a maximum period of four seconds. On the other hand it would have been possible to do downsizing on diesel engine as well as on the hydraulic pump maximum displacement and achieve e.g. fuel savings that way. However, even with the studied hybrid boost functionality, up to $20 \%$ fuel efficiency improvement was observed as the fuel consumption was measured in liters per harvested cubic meter of timber. In other words also increased production possibly had an effect on the fuel consumption comparison. The main drawback of such a simple energy storage system is however that not all of the energy storage capacity can be effectively used in the application, because as the accumulator pressure is lowered to the same level or under the actual circuit pressure - the stored energy is no more really useful. In mobile work machines as well as in vehicles in general it is not easy or economical to oversize the energy storage but on the contrary the installed capacity should be exploited in its entirety. This problem needs to be addressed with a more advantageous connection of the hydraulic accumulator to the hydraulic system. In a good solution most of the energy storage capacity of a hydraulic accumulator can be used in parallel also with the full system pressure in the work hydraulics.
Research related to hydraulic hybrids is often concentrating to vehicle propulsion and drive transmission systems as industrial production volumes and on the other hand also braking energy recovery possibilities there are remarkable. Rydberg is comparing electric and hydraulic hybrids, especially in the field of vehicle propulsion in his study [12] and states that hydraulic hybrid systems create a unique opportunity to optimize the engine loading at all speeds. Furthermore hydraulic machines are told to have around five times higher power density than electric machines, which is a great advantage when manufacturers are packing the components to limited space in the vehicles. Often the situation is also that the same machine layout should be possible to deliver with the hybrid solution as well as with the more traditional power train and this means that possibly needed extra room for hybrid system components can be hard to find. Higher power density is also stated to give the opportunity to use direct hydraulic drive and leave out mechanical gearing that is typically needed in electric hybrid systems. Interestingly, the roundtrip efficiency of a hydraulic accumulator is known to be higher than for the electric battery, especially in applications with frequent acceleration and braking. On the other hand it is quite obvious that an ultra-capacitor (UC) or a combination of batteries and UC would most likely make a better alternative to serve as energy storage of a highly dynamic electric hybrid application. However the cost level of ultra-capacitors is known to be relatively high.

One recent and interesting commercial activity on the narrow area of work machine hydraulic hybrids seems to be Caterpillar Inc. releasing its new 336E H Hydraulic hybrid excavator [19]. In this machine weighing $37.200 \mathrm{~kg}$ and having installed engine power of $230 \mathrm{~kW}$, the upper structure swing brake energy is stored to hydraulic accumulators and reused at the time of next swing acceleration. Not much technical facts are unfortunately available at the moment, but the manufacturer claims fuel savings as high as $25 \%$ compared to a respective machine unit with traditional hydraulic system. The improved fuel efficiency is said to give return on investment in as short time as one year, more typically in 18 months. Caterpillar is also stating that more than 300 patent applications were filed for the technology developed in the $336 \mathrm{E} \mathrm{H}$.

Also a number of other studies to improve the energy efficiency of hydraulically driven mobile work machines have been carried out earlier. Many of them have concerned various hydraulic energy recovery or boom balancing $[5,8]$ solutions that aim to increase hydraulic system efficiency by directly reusing potential or kinetic energy to other functions or storing the energy for later use. However these studies have been earlier discussed as boom dead weight balancing systems or potential energy recovery or reuse systems - more than hydraulic hybrid systems. 


\section{Power transmission system of a CTL harvester}

In a typical CTL harvester the harvester head is supported and moved with a purpose built hydraulic boom system in order to reach the trees to be felled and processed. Actually almost all power transmission in the machine is implemented by a hydraulic system and its actuators. In case of PONSSE Ergo harvester that can be seen in fig 6 - two independent open circuit hydraulic systems are used, one for the boom and another for the harvester head. The harvester head circuit is being fed by a $190 \mathrm{~cm}^{3}$ variable displacement pump with electrical maximum displacement control, the pressure level also being electrically adjustable in order to match these parameters accurately for each work phase and function. This way excess system flow and pressure can be satisfactorily avoided in most cases. By adjusting the maximum pump displacement the actuator speed can be controlled in a more efficient way than using throttling in proportional directional valves. One example of this is that the maximum feed speed of the log is limited with pump displacement and valve control is only used for more accurate positioning when approaching the desired cutting position on the tree stem.

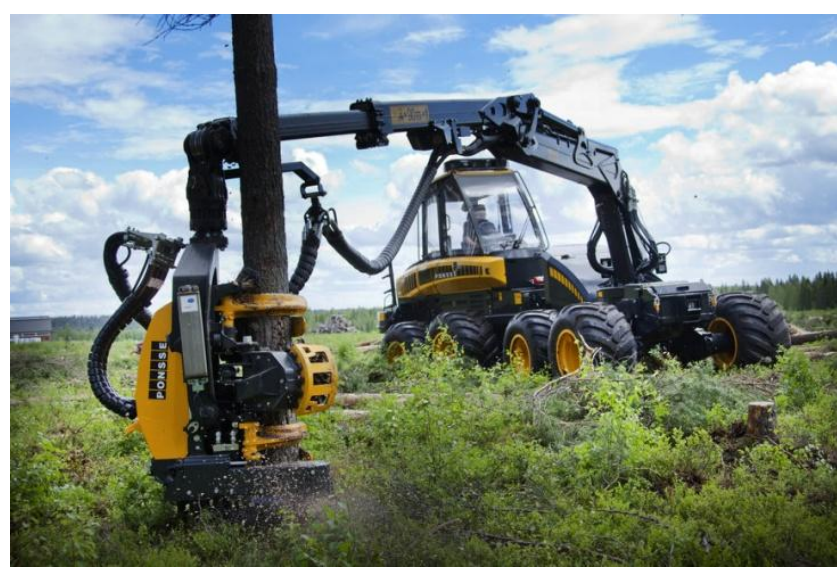

Figure 6. A Cut-To-Length harvester felling a tree on a full boom reach. Functions of crane and harvester head are often activated simultaneously and this creates high intermittent power demand. Photo: Ponsse Plc.

An embedded Arcnet / CAN bus based control system is managing these pressure and volume flow settings as well as reading the operator input and controlling the actuators of the system and the diesel engine that serves as the prime mover of the whole machine.

Variable displacement pump driving the boom system has a maximum displacement of $145 \mathrm{~cm}^{3}$ and is controlled with a Load Sensing (LS) governor as very typically in mobile work machine boom systems like this in order to achieve state of the art efficiency.

The hydraulic pumps of these circuits are driven with an Euromot Stage 3B compliant diesel engine with nominal power of 210 kW (@2200RPM) and torque of 1120 Nm (@
1200 to 1600 RPM) via a pump divider gear with two parallel outputs.

These two main hydraulic systems of a CTL harvester can generate remarkable power demand to the diesel engine especially when both boom and harvester head functions are utilized simultaneously during harvesting work. Other hydraulic circuits and functions are as well present within the machine, including hydrostatic drive transmission for example as well as hydraulic fluid filtration \& cooling circuits. More rarely also drive transmission can be used at the same time with harvester head and boom functions. The main hydraulic systems and their pump placement on the pump divider gear are generally shown in the fig. 7 .

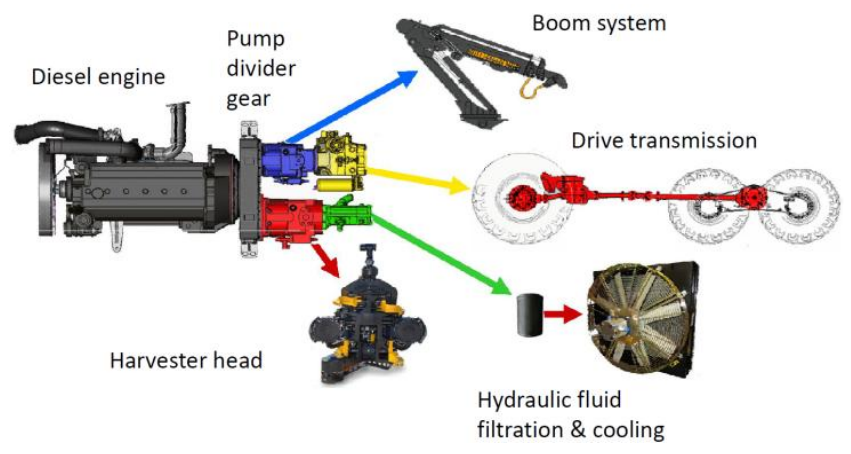

Figure 7. The main hydraulic system of a PONSSE Ergo harvester. Schematic figure by Ponsse Plc.

\subsection{Power demand and how to manage it}

The power demand from the prime mover is typically highly dynamic in a CTL harvester and for this reason the diesel engines typically need to be dimensioned for remarkably higher maximum power than the average harvesting work load. Furthermore diesel engines typically have their most fuel efficient working point in lower RPM range, in case of PONSSE Ergo between 1200 to 1400 RPM where the highest nominal power is not available and thus even more oversizing may be needed.

As the challenges caused by the harvester work cycle have been around for a while - there are a number of different approaches to manage these high-power, but typically shortduration power peaks, some of which being the following:

- dimensioning of the primary mover, typically diesel engine simply for the highest possible intermittent power demand

- use of power limiting governor and/or control approach on one or more of the variable displacement hydraulic pumps 
- forecasting and estimation of foreseeable power demand changes based on the knowledge on a typical work cycle and controlling the engine in beforehand and taking the advantage of the hydraulic system delays [6]

- Power demand estimation based on measured signals like tree stem diameter indirectly describing the needed power level for each individual tree to be processed [7]

However, measurements and experience has shown that the maximum power needed can be easily over twice the average power in a Cut-To-Length harvesters work cycle. In other words the present solution can not be the optimal one in terms of fuel efficacy or component dimensioning.

In history when engine exhaust emission regulations were not as strict as today, one way to improve engine dynamics in front of high step-like loads was to choose as heavy flywheel option for the engine as possible. This way the engine could a little easier go over rapid load transients. The drawback of this approach was of course excess weight and the fact that that engine RPM recovery was inconveniently slow if the engine was stalling after a little longer power demand. The prevailing diesel engine exhaust emission regulations [1] are however making the use of this approach practically impossible.

It is also possible to use power limiting governors on variable displacement pumps, but this is typically compromising the productivity and ruining the smooth and fast operation of a hydraulic boom system with expected high dynamic performance. On the other hand especially in harvester head circuit high intermittent power is simply needed in order to be able to cut through the thick tree branches with delimbing knives. This dynamical requirement of delimbing process and especially the acceleration phase at the start of the function are also depicted in the study by company HSM [2]. Also cross cutting process is very critical in terms of time and maximum power available as if the cut starting from the upper side of a $\log$ is too slow, the log will have too much time to be bent and this will damage the valuable sawmill logs with longitudinal splitting, so called end checks [15] that are known to be specially harmful problem for sawmill and veneer industry.

Also different ways to more intelligently control the engine of a forest machine exist on the market. Modern diesel engines with electronic engine control units (ECU) can be controlled with reasonably quick response. This way it may be advantageous to deliver a short extra RPM or fuel injection request to the engine as soon as it is clear that increase in engine load will take place soon. Typically in a harvester for example it takes some hundred milliseconds for the system pressure level to rise in harvester head circuit - after the feed or saw function is activated by the operator or an automatic control sequence. This delay gives the control system a possibility to tell the engine shortly beforehand that a load peak will be coming soon and the engine can prepare for that event with a more dynamic response [6].

Another proposed system is to measure the tree diameter when the harvester head grabs the tree to be processed [7]. Tree diameter value and possibly operator entered tree species could for example be the basis for engine control which basically could ask for more engine RPM or torque if the tree to be processed is bigger and thus most likely heavier to process than the earlier ones.

It is quite obvious that a suitable parallel hybrid system could be very useful in tackling these problems in an intelligent way. Therefore - parallel hybrid systems capable of evening out the power peaks of the work cycle are of great interest among forest machine manufacturers.

\section{Motivation}

As fuel prices have been rising remarkably, the fuel cost of a Cut-To-Length harvesting operation have already reached a level that can be compared to other factors of production in the harvesting process, for example operator labor cost on at least some market areas. Therefore more and more interest to novel solutions reducing the fuel consumption is brought to discussion. For example a Cut-to-length harvester can yearly run 1500 to 7000 work hours in the forest with a average fuel consumption of 10 to 15 liters per hour which will mean yearly fuel consumption of 15.000 to 105.000 liters. With diesel fuel prices exceeding of 1 Euro for liter, this clearly has a remarkable effect on the operating costs of such piece of work machinery.

Also in forestry sector - hybrid solutions are found attractive at seen at least from two different points of view, them being the one of an end user of the machinery as well as the one of the original equipment manufacturer (OEM).

\subsection{Motivation of engine downsizing for the forestry contractor and machine owner}

A machine with downsized engine and a hybrid system taking care of the short-duration, high-power peaks - will most likely be able to deliver better fuel economy of the logging operation. It is also possible that the engine response and dynamics can be even better than with a traditional solution - as hybrid system can provide high power to the system for the needed short times. This would help the operators to achieve higher productivity and in some cases also higher work quality. Especially crosscutting and delimbing quality is often compromised if the needed power and dynamics is not available during the work.

Furthermore - the use of a downsized engine will possibly result to more compact machine layout and for example better visibility and agility of the machinery as well as lowered noise and vibration levels at the operator's station. Typically - downsizing from a 6-cylinder diesel engine to 4cylinder engine cuts already $200 \ldots 300 \mathrm{~mm}$ of the engine length which actually could have an effect on the engine 
hood that is typically compromising the visibility as well as affecting the maneuverability of the machine.

Service and maintenance cost can also be lower for downsized smaller diesel engine which works assisted by a hybrid system evening out the heaviest loads.

\subsection{Motivation for the forestry equipment OEM}

Especially with the diesel engines meeting the latest exhaust regulations it has been noticed that not only the engine itself causes costs related to the power generation system. Also cooling system, exhaust after treatment (EGR, SCR, DPF etc.) systems etc. cause remarkable costs and require lot of room on the machine layout. These costs and component dimensions seem to be in relation in the first place to the engine displacement and on the other hand to the engine nominal power rating.

In other words a possibility to replace a 6-cylinder engine with a shorter, say 4-cylinder unit would not only free up the room right next to the engine, but also from other parts of the engine bay as engine cooler and exhaust systems will be smaller on the machine. With the right hybrid system design a small diesel engine combined with a hybrid system could perform as good as a larger displacement diesel engine without hybrid. Hybrid solution can also be attractive in terms of component and manufacturing costs but this is more case specific.

On the other hand a hybrid system could of course be used to provide power boost functionality to a present solution and make a higher productivity and performance possible without the need to increase the engine displacement and dimensions.

\section{Work cycle of a CTL harvester}

In order to evaluate the potential of a hybrid system in a harvester it is very important to know the work cycle in as many detail as possible. Therefore a set of measurements in actual harvesting work were carried out. Some details of the measurements are presented in the following.

\subsection{Work cycle measurements}

A large number of Arcnet/CAN bus signals were logged via the machine control system. Also some separately instrumented flow and pressure measurements were collected. An overview of over 60 signals altogether, logged or measured can be seen below:

- all operator entered input signals to the machine control system (boom control lever and harvester head function key signals, drive direction, drive speed etc.)

- a number of CANbus messages from the diesel engine (RPM, engine load percent, intermittent and cumulative fuel consumption data)
- $\quad$ system pressure and volume flow data (boom circuit volume flow, LS pressure and circuit pressure, harvester head circuit volume flow and pressure)

Measured work cycles were also captured on video in the same time domain in order to be able to trace each measured work phase also on the video for checking the actual work done with the machine.

Measured harvesting work included harvesting of different size trees in actual harvesting work. Diameter and length of each tree and $\log$ among other operator input data (log assortments, tree species etc.) was measured and automatically saved for each tree in a .stm file per StanForD standard (Standard for Forest machine Data and Communication) [17] with the harvester measurement system.

\subsection{Work cycle analysis}

It is well known that the work cycle of a CTL harvester typically consists of rather short duration duty cycles - that are - quite naturally linked to short phases of the actual harvesting work. This means processing the trees with the crane and the harvester head, in more detail including the following sub cycles:

- if needed - driving the machine to the next working position on the logging site

- moving the harvester head with the crane to the next tree and grabbing it

- felling the tree by cutting it with the high speed chain saw an directing the tree to fall to the desired direction

- feeding the tree trunk through the harvester head with the feed rollers and at the same time

- delimbing the tree with the delimbing knives

- as well as measuring and bucking the tree in desired dimensions with the cutting saw

- dropping the tree top to the ground by opening the feed rollers and delimbing knives and tilting the harvester head into the upright position

- moving the harvester head with the crane to the next tree and grabbing it

This work cycle related to processing of one tree is then normally repeated hundreds or thousands of times a day or during each work shift.

In fig 8 it can be seen how ten different main functions of a harvester machine are used during processing of two consecutive trees. 


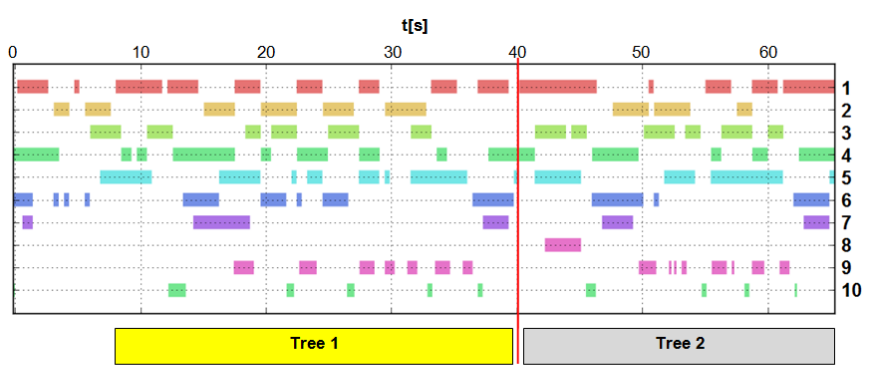

\begin{tabular}{|l|l|}
\hline 1. Boom slew LEFT & 6. Boom jib IN \\
2. Boom slew RIGHT & 7. Boom telescope IN \\
3. Boom lift DOWN & 8. Boom telescope OUT \\
4. Boom lift UP & 9. Tree feed ON \\
5. Boom jib OUT & 10. Cutting saw ON \\
\hline
\end{tabular}

Figure 8. Processing of two consecutive trees with a Ponsse Ergo harvester. Activation of 10 different harvester functions shown as a Gantt chart.

For example slightly longer cutting saw activations (function 10) are needed when the tree is being felled. These moments can be seen on the $\mathrm{t}[\mathrm{s}]$ axis at $\sim 12$ seconds and $~$ 47 seconds. The cross-cuts and feeding of the tree (function 9) are then taking turns as long as the whole tree is processed. In this case tree 1 obviously comprised of four logs and tree 2 of three $\operatorname{logs}$. It can be seen that during cutting and feeding also boom functions are used. Sometimes several functions simultaneously.

Of course the CTL harvester machine needs to be moved a short distance between work positions once in a while - but this propel function implemented with a hydrostaticmechanical drive transmission is not really important in typical work cycle of the machine type in terms of power demand or lifecycle fuel consumption. Thus the drive transmission is so far excluded in the study even if transmission data was also logged. On the other hand propelling of the machine is typically not used simultaneously with the tree processing functions - even if it is actually possible with some limitations.

It is clear that harvester head cutting saw as well as tree feeding roller rotation functions are the most important power consumers in a CTL harvester, also crane functions having a remarkable power need. Especially when two or more of these functions are activated at the same time - high power peaks can be observed in the hydraulic system as well as high torque values at the diesel engine.

Very typically these loads can be almost step-like load transients, which are difficult to handle for a diesel engine without compromising the exhaust emission levels. Especially the latest diesel engine exhaust emission regulations like the Euromot Stage $3 \mathrm{~A}$ and $3 \mathrm{~B}$ [1] have caused that the fact that engines have to be dimensioned to remarkably higher power level than the average power demand in a CTL harvester application.

Of course the actual power demand depends on the trees and the forest to be cut and processed but typical average power demand from PONSSE Ergo harvester can be lower than $100 \mathrm{~kW}$ even on a regeneration harvesting site - despite of which the engine is dimensioned to $210 \mathrm{~kW}$ in order to be able to handle the highest power peaks without compromising the productivity or processing quality. Also work methods of the operator and operator set system settings can have a remarkable influence on this power demand

In fig. 9 a measured typical power demand curve for harvesting work is shown. The maximum peak power demand level at this harvesting site seems to stay mainly below $180 \mathrm{~kW}$ level as the average power level is slightly over $80 \mathrm{~kW}$. Power peaks exceeding the average power are coded with red colour and power levels below average power is coded with blue colour. In other words the $210 \mathrm{~kW}$ engine is pretty much required to take care of these loads even if it is heavily oversized when compared to the average load. On the other hand tree size during the measurements was not the absolute maximum for this machine and the power demand will still be higher when working with larger timber.

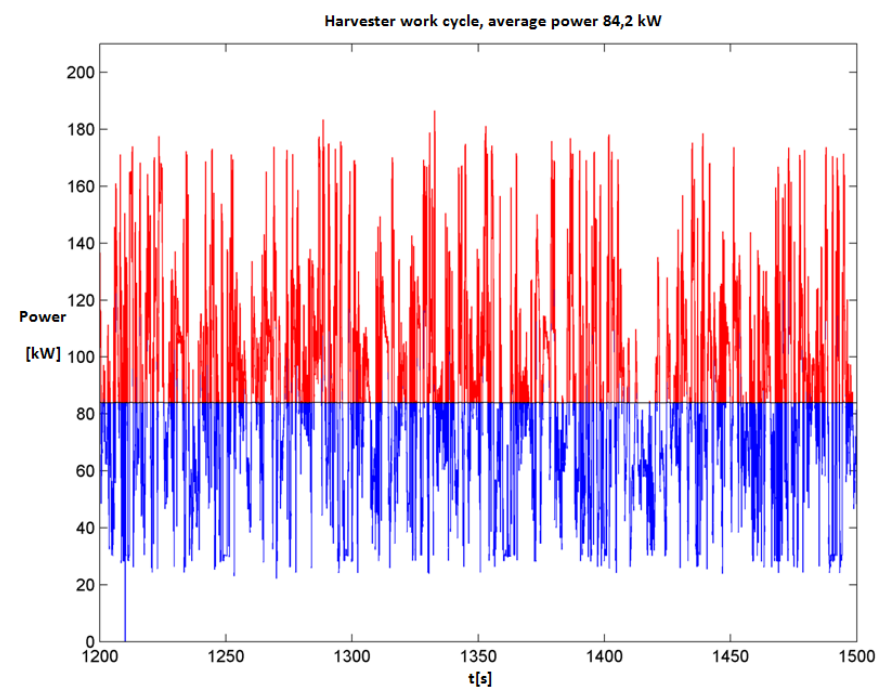

Figure 9. Actual power demand from the $210 \mathrm{~kW}$ diesel engine of a PONSSE Ergo harvester during 300 seconds of harvesting.

On the other hand if a constant output power of approximately $80 \mathrm{~kW}$ is taken from the diesel engine, the excess power needs to be taken care with the secondary power source, the hybrid system and its energy storage.

In fig. 10 a shorter seven second long section of the harvesting work zoomed in. It can be seen that power peaks typically last only short time, typically 1 to 2 seconds a couple at the time and then the power level comes down which would give us a chance of engine downsizing with reasonable energy storage dimensioning. 


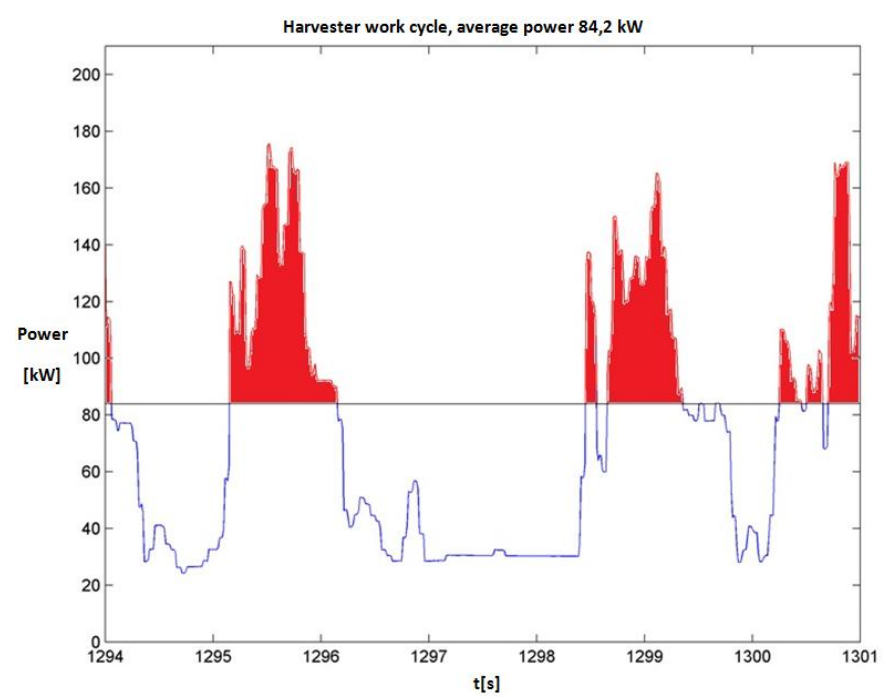

Figure 10. Actual power demand in $\mathrm{kW}$ from the $210 \mathrm{~kW}$ diesel engine of a PONSSE Ergo harvester during seven seconds of harvesting.

The energy / work of a single power peak can be determined as an area between the given constant (here average) power level and actual power curve. In other words by integrating the power curve over time from point $a$ to $b$ as shown in equation 1 .

$$
\mathrm{A}=\int_{\mathrm{a}}^{\mathrm{b}} f(t) d t
$$

Trivially - the basic principle to dimension a hybrid system to take care of the power peaks is to dimension its energy storage capacity as well as power transforming means to be able to handle the energy flows in an adequate manner.

Based on the measurements done in this study, a typical amount of energy needed from the hybrid system for a single power peak is typically around $100 \mathrm{~kJ}$, when calculated based on the average power. In this rough estimation hybrid system component losses are not considered. However in some parts of the work cycle there is not enough time available to keep the energy balance on the positive side with energy storage capacity of $100 \mathrm{~kJ}$, but more energy storage capacity is needed.

Energy balance of the energy storage and the hybrid system in general is discussed in fig. 11 which shows the calculated cumulative energy needed from the energy storage during the measured harvesting work cycle. This curve is calculated based on the assumption that the diesel engine only provides a constant power of $84,2 \mathrm{~kW}$ and all power exceeding this level is taken from the energy storage. From the curve in fig. 11 it can be seen that there are periods when the energy demand stays high for extended period of time. For example the part of the work cycle between moments $\mathrm{t}[\mathrm{s}] \sim 470$ seconds and $\sim 620$ seconds seems to require almost $1200 \mathrm{~kJ}$ of energy.

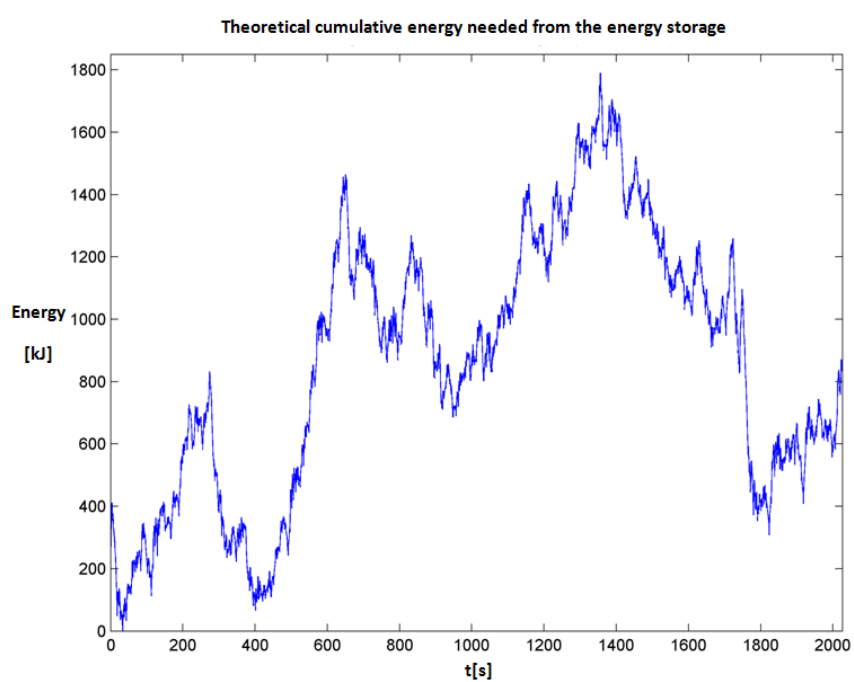

Figure 11. Theoretical cumulative energy needed from the energy storage during measured harvesting work cycle based on the assumption that diesel engine provides constant power of $84,2 \mathrm{~kW}$ and everything exceeding that is taken from the energy storage.

On the other hand if the aim is to look for engine downsizing from the starting point of $210 \mathrm{~kW}$ 6-cylinder engine, we can choose for example $145 \mathrm{~kW}$ or $129 \mathrm{~kW} 4-$ cylinder engine and still take away two cylinders as well as downsize engine displacement dependent add-on systems like cooling system and exhaust gas after treatment. Anyhow - this extra power margin over the average power level allows the engine load to be higher also for little longer times - and still keep the energy balance of the hybrid drive on the positive side. It may also be a good idea to think about allowing the diesel engine to operate on variable or adaptive power level depending on the actual work conditions. Also different kind of hybrid operation modes can possibly be taken into implementation - for example one setting or mode could aim for lowest fuel consumption but as a drawback, performance would be possibly more or less limited. Respectively another setting could aim for maximum performance or "power boost" functionality, but most likely compromising the fuel efficiency.

However a rough estimate for the needed energy storage capacity for engine downsized PONSSE Ergo hybrid harvester could be about $300 \mathrm{~kJ}$ to $500 \mathrm{~kJ}$, which is still reasonable to implement also with hydraulic accumulators as well as with electric energy storage systems. 


\section{Choosing the hybrid system}

Choosing the right hybrid solution for a CTL forest machine needs to be done based on the work cycle. First of all in this study a harvester machine is only considered as it seems to be the more interesting machine type in terms of load cycle. In other words harvester load cycle is thought to be more difficult and dynamic than the one of a forwarder and thus the potential for hybrid system payback would be better.

Then choosing between electric and hydraulic hybrids is the next question. Hydraulic hybrid seems to have a number of clear advantages compared to electric hybrids. Some facts that stand for hydraulic hybrid in CTL harvester application are discussed hereinafter.

Naturally it is a good idea to avoid all unnecessary energy conversions if possible, because every conversion causes losses. Almost all of the functions in a CTL harvester are implemented hydraulically and with hydraulic actuators mainly because of the high power to size \& weight ratio. If an electric hybrid system would be chosen that would naturally mean more energy conversions between electric and hydraulic energy which should be avoided. Possibly some of the forest machine functions could be direct electric drive, but not the majority. For example replacement of hydraulics in forest machine boom systems and especially in the harvester head simply does not seem to be realistic in the near future.

On the other hand forest machinery manufacturers as well as their dealer and service network are familiar with hydraulic power transmission and also energy storing into hydraulic accumulators as on the opposite - high current and voltage electric hybrid drives are often totally unknown technology in the business. This would mean very high requirements on service people training and most likely demand for officially qualified electricians in the service organization.

On the other hand it is a fact that forest machines rarely work close to infrastructure like power grid - where electrical energy could be available to introduce plug-in functionality. This possibility for example by charging energy storage from grid could be an interesting topic for mining, earthmoving or material handling machinery that may operate extended times close to energy available from the electric grid and sufficient energy storage capacity could be mounted on board.

Forest machines also work in really harsh circumstances and also service often has to be possible on site in the forest. A special requirement for all forest machine systems is that they need to be performing in both cold and hot ambient temperatures, say from $-40^{\circ} \mathrm{C}$ to $+40^{\circ} \mathrm{C}$. On the northern hemisphere the most important logging season is during the mid winter when ground frost makes the access to thinning sites and wetlands possible. On the other hand fast growing eucalypt plantations are typically located in the southern hemisphere where high ambient temperatures ask for the maximum cooling capacity from the machine. Cold start does not need to be possible in the coldest weather but as the machine have been started the continuation of the -logging operation has to be possible. Concerning hybrid systems especially electric battery system performance seem to be a problem in cold temperatures. Also a hydraulic accumulator needs to be assembled with the right materials and taken into use the right way in cold start - but these problems seem to be a little easier to overcome.

Finally the cost factors also seem to be advantageous for hydraulic hybrid - at least in harvester application where the nature of hybrid system is power peak management with reasonably small energy storage capacity needed. The costs between electric and hydraulic hybrids have been compared in a number of studies and typically hydraulic hybrid is considered to be remarkably more economical. According to hydraulic accumulator manufacturers cost effectiveness is better on hydraulic energy storage as seen in fig 12. Also other main characteristics seem to be positive.

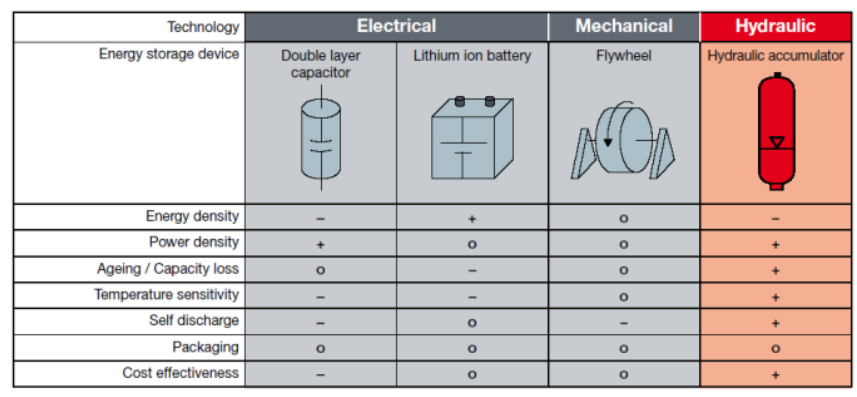

Figure 12. Comparison of energy storage devices by Hydac. [16]

The main drawback of a hydraulic hybrid seems to be the somewhat limited energy storage capacity of hydraulic accumulators. Possibly also controlling of the hydraulic energy flow between the work hydraulic system and the energy storage, especially in highly dynamic operation can be more challenging than in electric hybrid systems. Both these drawbacks are however much related to the actual application. For example a somewhat limited energy storage capacity is not a crucial problem if full hybrid driving is not needed at all which is the case in this study.

The energy storage capacity of a hydraulic accumulator is demonstrated in fig 13 [16]. The size of the hydraulic accumulator in this example could roughly provide the energy storage capacity needed in the CTL harvester discussed in this paper. The energy capacity of $360 \mathrm{~kJ}$ can be used in 6 seconds at constant power of $60 \mathrm{~kW}$. On the other hand this 50L accumulator can provide a power of 100 $\mathrm{kW}$ for 3,6 seconds - which should be long enough time to handle most of the power peaks in the measured harvesting work cycle. 


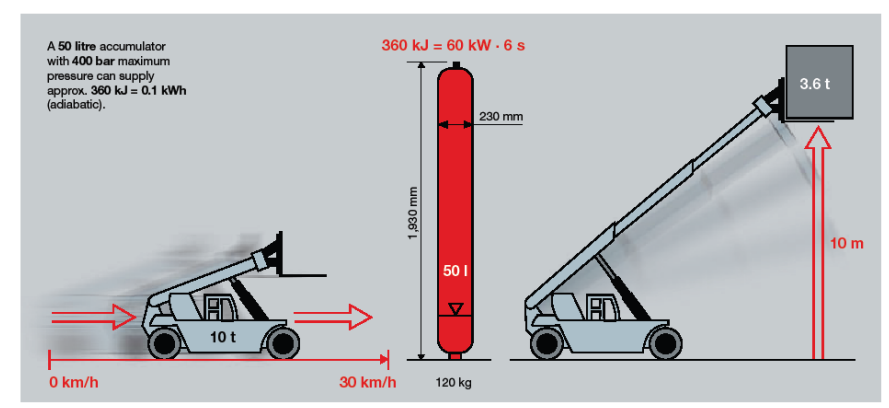

Figure 13. Demonstration of energy storage capacity of a hydraulic accumulator of volume $50 \mathrm{~L}$ and maximum pressure of 400 bar. [16]

The charge - discharge rate of the energy storage will be an important issue as we know the load cycle being very dynamic. From fig 9 we could see that a typical charge discharge cycle of a CTL harvester only lasts about two seconds. With electrical energy storage this kind of dynamics seems to be achievable only with ultra capacitor at least as a part of the energy storage system. A comparison of various energy storage systems is telling that different designs of hydraulic accumulators are very competitive with electrical ultra capacitors in terms of charge - discharge rate. Electrical batteries are told to have a cycle time starting from one minute so they can not be a good solution, definitely not as the only energy storage. Also round trip efficiency of an electric battery is stated to be lower than the one of a hydraulic accumulator [5].

In other words hydraulic accumulator should be well able to cope with the dynamical requirements set by the short cycle time of this CTL harvester application under the study.

\subsection{Proposed hydraulic hybrid system}

Finally a very simple hydraulic hybrid system for a Cut-ToLength harvester is proposed in fig. 14. The hybrid system pump-motor 2 is added on the same driveline as present pump 1 serving the harvester work hydraulics. A separate over-center controllable closed circuit pump-motor 2 is needed to control the oil and energy flow between the hydraulic system and the energy storage that is a pressure accumulator or set of them.

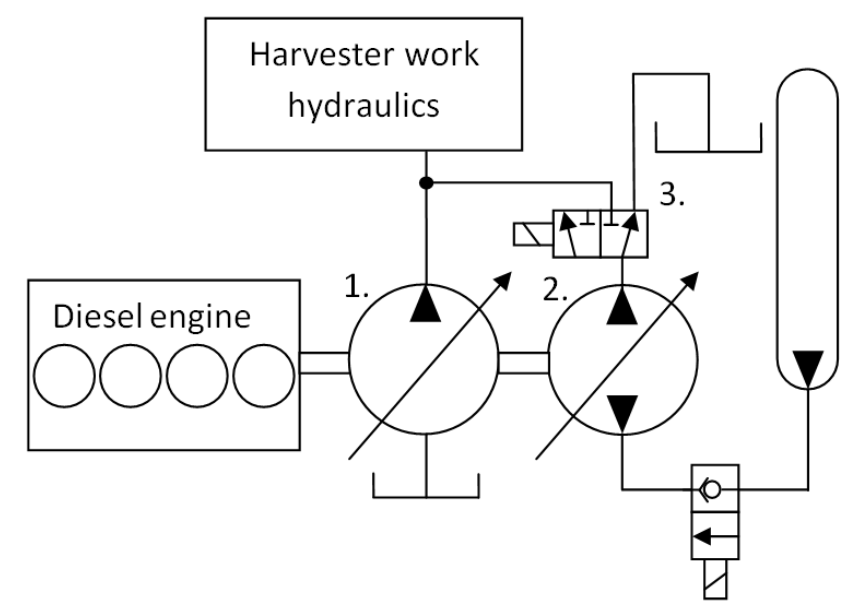

Figure 14. A simplified hydraulic hybrid system of a CTL harvester.

During low power demand of the actual work cycle the pump-motor 2 is delivering the hydraulic energy into a higher pressure to the hydraulic accumulator and during high power demand - respectively feeding the power from the hydraulic accumulator into the harvester work hydraulics through the pump-motor 2 .

Pump-motor 2 could also be connected directly to the tank from the work hydraulics side with e.g. a $2 / 3$ directional valve 3 for example - and this way stored energy could simply be used to feed assist torque and power to drive pump 1 and the diesel engine as well as any other pumps and devices on the same mechanical drive train.

The proposed system is expected to be able to effectively use the installed energy storage capacity thanks to the variable displacement pump-motor 2 used also as a pressure converter unit. Furthermore this same unit, principally a standard pump more typically used in closed loop hydrostatic drive transmissions, has good possibilities to control the charge-discharge process accurately without needed extra valves. However the dynamics of the pumpmotor 2 as a component as well as its control approach will possibly pose challenges as the cycle time in a CTL harvester application is rather short, presumably less than two seconds. If the dynamic properties of pump-motor turn out to be inadequate - one possibility also worth studying could be to look for direct discharge or boost valve directly from the pressure accumulator to the system - bypassing pump-motor 2.

As downsizing is discussed - in addition to the diesel engine downsizing - also the original variable displacement pump 1 should be downsized as volume flow demand in the proposed system is divided for two pumps in place of earlier single pump.

Energy recovery functionality from different subsystems of the CTL harvester can also be discussed in the future as remarkable energy storage capacity is installed on the machine. 


\section{Conclusions}

There seems to be promising possibilities for a hydraulic hybrid system to help the machine manufacturers with the power management of a CTL harvester machine.

Hydraulic accumulator seems to be a suitable energy storage for CTL harvester application because the overall nature of power peaks in the work cycle seem to be short-duration and high-power.

The dimensioning as well as control principle of the hydraulic hybrid system needs to be discussed in more detail in the future. It is clear that simulation can be a useful tool in order to determine the energy balance of various work cycles and machine configurations as well as to study the dynamical behavior of the pump-motor connecting the energy storage to the hydraulic system.

\section{Proposed future work}

Next phases of this ongoing study will include simulation of the hydraulic hybrid system of a harvester. Diesel engine model is possibly also needed to take into consideration and interaction with the hybrid power transmission system. Then, based on the simulations the system components can be dimensioned and chosen. System will need hydraulic energy storage like set of hydraulic accumulators as well as suitable over-center closed circuit pump-motor for connecting the energy storage to the hydraulic system. Simulation can also give important information about the dynamical requirements that are set by the work cycle to the pump-motor and its control. So far the efficiency of the components needed in the hydraulic hybrid have been more or less ignored and they have to be taken into account in future work.

After the simulations and component selection - possibility of test / prototype machine assembly is to be considered. With the actual machine real scale fuel economy measurements could be done in harvesting work and compared to a respective machine with traditional power system.

The right design of the energy storage, say hydraulic accumulators also need to be chosen carefully taking the performance, cost and room as well as placement constraints into account. For example the installation position of large bladder accumulators is more limited than the one of piston accumulators for example.

\section{References}

[1] N.N. Directive 97/68/EC of the European Parliament and of the Council of 16 December 1997 on the approximation of the laws of the Member States relating to measures against the emission of gaseous and particulate pollutants from internal combustion engines to be installed in non-road mobile machinery. Official Journal L 059 , 27/02/1998 P. 0001 - 0086. 1998.
[2] Felix Prinz zu Hohenlohe. Phlegmatisierung als Tugend in der Mobilhydraulik - Das Energiespeichersystem des Kranvollernters HSM 405H2. Karlsruher Schriftenreihe Fahrzeugsystemtechnik 3. Fachtagung - Hybridantriebe für Arbeitsmaschinen. Karlsruhe, 2011.

[3] L.Lundström, Electrically propulsed vehicle, International Patent Application WO2005/047042, 2005 .

[4] J. Morinaga, T. Kawaguchi, H. Inoue. Power generation control method of hybrid construction machine and hybrid construction machine, US Patent 8,207,708B2, 2012.

[5] R. Späth, T. Landmann, D. Boehm. Energierückgewinnungskonzepte bei Hydraulikbaggern. 5. Fachtagung Baumaschinentechnik 2012. 2012.

[6] K. Einola, V. Rintamäki. Method for controlling a power source of a forest machine, US Patent 7,802,595B2, 2010.

[7] J. Järvinen, O. Hankamäki, P. Karjalainen. A Method in controlling an engine of a forest machine and a forest machine. International Patent Application WO03/096794, 2003.

[8] W. Sun, T. Virvalo. Simulation study on a hydraulicaccumulator-balancing energy-saving system in hydraulic boom. Proceedings of the $50^{\text {th }}$ National Conference on Fluid Power. March 16-18 2005, Las Vegas, Nevada USA pp. 371-381.

[9] N.N. Komatsu Ltd. Press Release 2008/05/13. 2008. Komatsu Corporate Communications. Retrieved 25.3.2013 from: http://www.komatsu.com/CompanyInfo/press/2008051 315113604588.html

[10] Jönsson A. Weg vom Öl, Forstpraxis.de, Forst \& Technik 21.01.2013. 2013. Retrieved 25.3.2013 from: http://www.forstpraxis.de/weg-vom-oel

[11]N.N. ProSilva Plc. Press Release 31.8.2013. Finland. Retrieved 25.3.2013 from: http://www.prosilva.fi/images/stories/pdf/pressrelease.p $\underline{\mathrm{df}}$

[12] Rydberg K-E. Energy Efficient Hydraulic Hybrid Drives. The 11th Scandinavian International Conference on Fluid Power. Linköping, Sweden June 2-4. 2009. Linköping University, Department of Management and Engineering.

[13] N.N. Mercedes-Benz UK Ltd. Press release 03-JAN2013. United Kingdom. Retrieved 25.3.2013 from: http://www.mercedes-benzmedia.co.uk/doc/2367/70121mer.doc 
[14] Abebayo B. Productivity and cost of Cut-to-Length and Whole-Tree harvesting in a mixed-conifer stand. July 2006. University of Idaho. USA.

[15] J. Inberg, J. Mattila, T. Virvalo. Harvester boom tip acceleration control during a crosscutting - Theoretical background. International Journal of Forest Engineering, Volume 13, Number 1. 2002 . Tampere University of Technology, Finland.

[16] N.N. Hydac International Gmbh. Hydraulic accumulators in hybrid technology. E 10.140.0/05.12. Retrieved 25.3.2013 from: www.hydac.com

[17] N.N. Skogforsk. StanForD - Listing of variables by category, Version 2012-04-18. Retrieved 27.4.2013 from:

http://www.skogforsk.se/PageFiles/60712/AllVarGrp_E NG_120418.pdf

[18]P. Achten, S. Eggenkaemp, V. Georges. THE EHYDRID. - The Twelfth Scandinavian International Conference on Fluid Power, May 18-20, 2011, Tampere, Finland.

[19] N.N. Caterpillar Inc. Press release 15-APR-2013. CAT ${ }^{\circledR}$ 336E H Hydraulic Hybrid Excavator Delivers NoCompromise, Fuel-Saving Performance. Retrieved 27.4.2013 from: http://www.cat.com/cda/layout?m=343975\&x=7\&id=4 $\underline{375050}$

[20] N.N. PSA Peugeot Citroen. Dossier de Presse 22.1.2013. Hybrid Air - an innovative petrol full-hybrid solution. Retrieved 27.4.2013 from: http://www.psapeugeotcitroen.com/sites/default/files/content_files/presskit_hybrid-air_en.pdf

[21] N.N. Eaton Corporation. Hydraulic Launch Assist Refuse Truck. 2009. Retrieved 27.4.2013 from: http://www.eaton.com/ecm/groups/public/@pub/@eato n/@hyd/documents/content/ct_234114.pdf 